\title{
Common fixed-point results in uniformly convex Banach spaces
}

\author{
Naknimit Akkasriworn' ${ }^{1}$ Annop Kaewkhao ${ }^{1 *}$, Attapol Keawkhao ${ }^{2}$ and Kritsana Sokhuma ${ }^{3}$
}

"Correspondence:

tor_idin@buu.ac.th

'Department of Mathematics,

Faculty of Science, Burapha

University, Chonburi, 20131,

Thailand

Full list of author information is

available at the end of the article

\begin{abstract}
We introduce a condition on mappings, namely condition $(K)$. In a uniformly convex Banach space, the condition is weaker than quasi-nonexpansiveness and weaker than asymptotic nonexpansiveness. We also present the existence theorem of common fixed points for a commuting pair consisting of a mapping satisfying condition $(K)$ and a multivalued mapping satisfying conditions $(E)$ and $\left(C_{\lambda}\right)$ for some $\lambda \in(0,1)$.
\end{abstract}

Keywords: common fixed point; quasi-nonexpansive mapping; generalized nonexpansive mapping; uniformly convex Banach space

\section{Introduction}

In 1978, Itoh and Takahashi [1] established the existence of common fixed points of a quasi-nonexpansive mapping and a multivalued nonexpansive mapping by an elementary constructive method in a Hilbert space. In 2006, Dhompongsa et al. [2] obtained a common fixed point result for a commuting pair of single-valued and multivalued nonexpansive mappings in uniformly convex Banach spaces. The analogy result in CAT(0) spaces was also proved by Dhompongsa et al. [3]. Since then, Shahzad and Markin [4] studied an invariant approximation problem and provided sufficient conditions for the existence of $z \in E \subseteq X$ such that $d(z, y)=\operatorname{dist}(y, E)$ and $z=t(z) \in T(z)$, where $y \in X, t$ and $T$ are commuting nonexpansive mappings on $E$. In 2009, Shahzad [5] also obtained a common fixed point and invariant approximation result in a CAT(0) space in which $t$ and $T$ are weakly commuting.

Motivated by Suzuki's result [6], Garcia-Falset et al. [7] introduced two kinds of generalizations for condition $(C)$, namely conditions $(E)$ and $\left(C_{\lambda}\right)$ and studied both the existence of fixed points and their asymptotic behavior. Recently, Abkar and Eslamian [8] proved that if $E$ is a nonempty closed convex and bounded subset of a complete CAT(0) space $X$, $t: E \rightarrow E$ is a single-valued quasi-nonexpansive mapping, and $T: E \rightarrow \mathrm{KC}(E)$ is a multivalued mapping satisfying conditions $(E)$ and $\left(C_{\lambda}\right)$ for some $\lambda \in(0,1)$ such that $t$ and $T$ are weakly commuting, then there exists a point $z \in E$ such that $z=t(z) \in T(z)$. This result was extended to the general setting of uniformly convex metric spaces by Laowang and Panyanak [9].

In this paper, we first introduce the following condition.

Definition 1.1 Let $t$ be a mapping on a subset $E$ of a Banach space $X$. Then $t$ is said to satisfy condition $(K)$ if

1. the fixed point set Fix $(t)$ is nonempty closed and convex, and

o 2012 Akkasriworn et al: licensee Springer. This is an Open Access article distributed under the terms of the Creative Commons Attribution License (http://creativecommons.org/licenses/by/2.0), which permits unrestricted use, distribution, and reproduction in any medium, provided the original work is properly cited. 
2. for every $x \in \operatorname{Fix}(t)$, a closed convex subset $A$ with $t(A) \subseteq A$, and $y \in A$ such that $\|x-y\|=\operatorname{dist}(x, A)$, we have $y \in \operatorname{Fix}(t)$.

We show that, in a uniformly convex Banach space, condition $(K)$ is weaker than quasinonexpansiveness and weaker than asymptotic nonexpansiveness. We also present the existence theorem of common fixed points for a commuting pair consisting of a mapping satisfying condition $(K)$ and a multivalued mapping satisfying conditions $(E)$ and $\left(C_{\lambda}\right)$ for some $\lambda \in(0,1)$. Consequently, such a theorem extends many results in the literature.

\section{Preliminaries}

In this section, we give some preliminaries.

A mapping $t$ on a subset $E$ of a Banach space $X$ is called an asymptotically nonexpansive mapping if for each $n \in \mathbb{N}$, there exists a positive constant $k_{n} \geq 1$ with $\lim _{n \rightarrow \infty} k_{n}=1$ such that

$$
\left\|t^{n}(x)-t^{n}(y)\right\| \leq k_{n}\|x-y\| \quad \text { for all } x, y \in E .
$$

If $k_{n} \equiv 1$ for all $n \in \mathbb{N}$, then $t$ is called a nonexpansive mapping. We denote by Fix $(t)$ the set of fixed points of $t$, i.e., $\operatorname{Fix}(t)=\{x \in E: x=t(x)\}$.

We shall denote by $\mathrm{FB}(E)$ the family of nonempty bounded closed subsets of $E$ and by $\mathrm{KC}(E)$ the family of nonempty compact convex subsets of $E$. Let $H(\cdot, \cdot)$ be the Hausdorff distance on $\mathrm{FB}(X)$, i.e.,

$$
H(A, B)=\max \left\{\sup _{a \in A} \operatorname{dist}(a, B), \sup _{b \in B} \operatorname{dist}(b, A)\right\}, \quad A, B \in \mathrm{FB}(X),
$$

where $\operatorname{dist}(a, B)=\inf \{\|a-b\|: b \in B\}$ is the distance from the point $a$ to the subset $B$.

A multivalued mapping $T: E \rightarrow \mathrm{FB}(X)$ is said to be nonexpansive if

$$
H(T(x), T(y)) \leq\|x-y\| \quad \text { for all } x, y \in E .
$$

Definition 2.1 A multivalued mapping $T: X \rightarrow \mathrm{FB}(X)$ is said to satisfy condition $\left(E_{\mu}\right)$ provided that

$$
\operatorname{dist}(x, T(y)) \leq \mu \operatorname{dist}(x, T(x))+\|x-y\|, \quad \forall x, y \in X .
$$

We say that $T$ satisfies condition $(E)$ whenever $T$ satisfies $\left(E_{\mu}\right)$ for some $\mu \geq 1$.

Definition 2.2 A multivalued mapping $T: X \rightarrow \mathrm{FB}(X)$ is said to satisfy condition $\left(C_{\lambda}\right)$ for some $\lambda \in(0,1)$ provided that

$$
\lambda \operatorname{dist}(x, T(x)) \leq\|x-y\| \quad \Rightarrow \quad H(T(x), T(y)) \leq\|x-y\|, \quad \forall x, y \in X
$$

A point $x$ is called a fixed point for a multivalued mapping $T$ if $x \in T(x)$. A single valued mapping $t: E \rightarrow E$ and a multivalued mapping $T: E \rightarrow \mathrm{FB}(E)$ are said to be commute if $t(T(x)) \subseteq T(t(x))$ for all $x \in E$. 
A Banach space $X$ is said to be strictly convex if

$$
\|x+y\|<2
$$

for all $x, y \in X$ with $\|x\|=\|y\|=1$ and $x \neq y$. We recall that a Banach space $X$ is called uniformly convex (Clarkson [10]) if, for each $\varepsilon>0$, there is a $\delta>0$ such that if $\|x\|=\|y\|=1$ then

$$
\left\|\frac{(x+y)}{2}\right\| \leq 1-\delta
$$

It is obvious that uniform convexity implies strict convexity.

In 1991, Xu [11] proved the characterization of uniform convexity as follows.

Theorem 2.3 [11] A Banach space $X$ is uniformly convex if and only iffor each fixed number $r>0$, there exists a continuous function $\varphi:[0, \infty) \rightarrow[0, \infty), \varphi(s)=0 \Leftrightarrow s=0$, such that

$$
\|\lambda x+(1-\lambda) y\|^{2} \leq \lambda\|x\|^{2}+(1-\lambda)\|y\|^{2}-\lambda(1-\lambda) \varphi(\|x-y\|)
$$

for all $\lambda \in[0,1]$ and all $x, y \in X$ such that $\|x\| \leq r$ and $\|y\| \leq r$.

Let $E$ be a nonempty closed and convex subset of a Banach space $X$ and $\left\{x_{n}\right\}$ be a bounded sequence in $X$. For $x \in X$, define the asymptotic radius of $\left\{x_{n}\right\}$ at $x$ as the number

$$
r\left(x,\left\{x_{n}\right\}\right)=\limsup _{n \rightarrow \infty}\left\|x_{n}-x\right\| .
$$

Let

$$
r \equiv r\left(E,\left\{x_{n}\right\}\right):=\inf \left\{r\left(x,\left\{x_{n}\right\}\right): x \in E\right\}
$$

and

$$
A \equiv A\left(E,\left\{x_{n}\right\}\right):=\left\{x \in E: r\left(x,\left\{x_{n}\right\}\right)=r\right\} .
$$

The number $r$ and the set $A$ are, respectively, called the asymptotic radius and asymptotic center of $\left\{x_{n}\right\}$ relative to $E$. It is known that $A\left(E,\left\{x_{n}\right\}\right)$ is as nonempty, weakly compact and convex as $E$ is [12]. The sequence $\left\{x_{n}\right\}$ is called regular relative to $E$ if $r\left(E,\left\{x_{n}\right\}\right)=r\left(E,\left\{x_{n_{k}}\right\}\right)$ for each subsequence $\left\{x_{n_{k}}\right\}$ of $\left\{x_{n}\right\}$.

Goebel [13] and Lim [14] proved the following lemma.

Lemma 2.4 Let $\left\{x_{n}\right\}$ be a bounded sequence in $X$, and let $E$ be a nonempty closed convex subset of $X$. Then $\left\{x_{n}\right\}$ has a subsequence which is regular relative to $E$.

The following result was proved by Goebel and Kirk [15].

Lemma 2.5 Let $\left\{z_{n}\right\}$ and $\left\{w_{n}\right\}$ be bounded sequences in a Banach space $X$, and let $0<\lambda<1$. If, for every natural number $n$, we have $z_{n+1}=\lambda w_{n}+(1-\lambda) z_{n}$ and $\left\|w_{n+1}-w_{n}\right\| \leq\left\|z_{n+1}-z_{n}\right\|$, then $\lim _{n \rightarrow \infty}\left\|w_{n}-z_{n}\right\|=0$. 


\section{Main results}

We recall that a mapping $t$ on a subset $E$ of a Banach space $X$ is called quasi-nonexpansive [16] if $\|x-t(y)\| \leq\|x-y\|$ for all $y \in E$ and $x \in \operatorname{Fix}(t)$. From the definition, we can see that nonexpansive mappings with a fixed point are quasi-nonexpansive.

We first show that a quasi-nonexpansive mapping defined on a strictly convex Banach space $X$ satisfies condition $(K)$.

Proposition 3.1 Let $E$ be a strictly convex subset of a Banach space. If $t: E \rightarrow E$ is a quasinonexpansive mapping, then $t$ satisfies condition $(K)$.

Proof It is known that $\operatorname{Fix}(t)$ is nonempty closed and convex [17, Theorem 1]. Let $x \in \operatorname{Fix}(t)$ and $A$ be a closed convex subset with $t(A) \subseteq A$. Let $y \in A$ be such that $\|x-y\|=\operatorname{dist}(x, A)$. Quasi-nonexpansiveness of $t$ implies that

$$
\|x-t(y)\| \leq\|x-y\|
$$

Since $E$ is strictly convex and $t(A) \subseteq A$, it must be the case that $t(y)=y$. Therefore, $t$ satisfies condition $(K)$.

An asymptotically nonexpansive mapping defined on a uniformly convex Banach space also satisfies condition $(K)$.

Proposition 3.2 Let $X$ be a uniformly convex Banach space and $E$ be a nonempty subset of X. If $t: E \rightarrow E$ is an asymptotically nonexpansive mapping with $\operatorname{Fix}(t) \neq \varnothing$, then $t$ satisfies condition $(K)$.

Proof The set Fix $(t)$ is closed and convex [18, Theorem 2]. Let $x \in \operatorname{Fix}(t), A$ be a closed convex subset of $E$ with $t(A) \subseteq A$, and $y \in A$ be such that $\|x-y\|=\operatorname{dist}(x, A)$. By Theorem 2.3, there exists a continuous function $\psi$ such that for all integers $l, m \geq 1$,

$$
\begin{aligned}
\left\|x-\left(\frac{t^{l}(y)+t^{m}(y)}{2}\right)\right\|^{2} & \leq \frac{1}{2}\left\|x-t^{l}(y)\right\|^{2}+\frac{1}{2}\left\|x-t^{m}(y)\right\|^{2}-\frac{1}{4} \varphi\left(\left\|t^{l}(y)-t^{m}(y)\right\|\right) \\
& \leq \frac{1}{2} k_{l}^{2}\|x-y\|^{2}+\frac{1}{2} k_{m}^{2}\|x-y\|^{2}-\frac{1}{4} \varphi\left(\left\|t^{l}(y)-t^{m}(y)\right\|\right) .
\end{aligned}
$$

Since $\|x-y\|=\operatorname{dist}(x, A)$ and $A$ is convex, we have

$$
\|x-y\|^{2} \leq\left\|x-\left(\frac{t^{l}(y)+t^{m}(y)}{2}\right)\right\|^{2} .
$$

Thus,

$$
\varphi\left(\left\|t^{l}(y)-t^{m}(y)\right\|\right) \leq 4\left(\left(k_{l}^{2}+k_{m}^{2}\right) / 2-1\right)\|x-y\|^{2} .
$$

Since $t$ is asymptotically nonexpansive, the right-hand side of the inequality tends to zero as $l, m$ tend to infinity. Hence, $\left\{t^{i}(y)\right\}$ is a Cauchy sequence. Let $\lim _{i \rightarrow \infty} t^{i}(y)=z \in A$. We have

$$
\left\|t(z)-t^{i+1}(y)\right\| \leq k_{1}\left\|z-t^{i}(y)\right\| .
$$


By letting $i \rightarrow \infty$, we can conclude that $\|t(z)-z\| \leq 0$, that is $z \in \operatorname{Fix}(t)$. Now, letting $l, m \rightarrow \infty$ in (3.1) yields

$$
\|x-z\|^{2} \leq\|x-y\|^{2}
$$

Since $z \in A$ and $\|x-y\|=\operatorname{dist}(x, A)$, thus $y=z$. Therefore, $y \in \operatorname{Fix}(t)$.

The following example shows that the class of mappings satisfying condition $(K)$ is strictly wider than the class of quasi-nonexpansive mappings and asymptotically nonexpansive mappings.

Example 3.3 Let $f$ be a function on $[0,1]$ defined by

$$
f(x)= \begin{cases}x, & x \leq \frac{1}{2} \\ 0, & x>\frac{1}{2}\end{cases}
$$

Then $f$ is neither quasi-nonexpansive nor asymptotically nonexpansive. However, $f$ satisfies condition $(K)$.

We are now in a position to state our main theorem.

Theorem 3.4 Let $E$ be a nonempty bounded closed convex subset of a uniformly convex Banach space X. Let $t: E \rightarrow$ E be a mapping satisfying condition $(K)$, and let $T: E \rightarrow \mathrm{KC}(E)$ be a multivalued mapping satisfying conditions $(E)$ and $\left(C_{\lambda}\right)$ for some $\lambda \in(0,1)$. If t and $T$ are commute, then they have a common fixed point, that is, there exists a point $z \in E$ such that $z=t(z) \in T(z)$.

Proof Commutative property of $t$ and $T$ implies that $t(T(x)) \subseteq T(x)$ for all $x \in \operatorname{Fix}(t)$. Then we have $\operatorname{Fix}(t) \cap T(x) \neq \varnothing$ for all $x \in \operatorname{Fix}(t)$ since $t$ satisfies condition $(K)$.

Now, we find an approximate fixed point sequence in $\operatorname{Fix}(t)$ for $T$. Take $x_{0} \in \operatorname{Fix}(t)$. Since $\operatorname{Fix}(t) \cap T\left(x_{0}\right) \neq \varnothing$, we choose $y_{0} \in \operatorname{Fix}(t) \cap T\left(x_{0}\right)$. Define

$$
x_{1}=(1-\lambda) x_{0}+\lambda y_{0} .
$$

Since $\operatorname{Fix}(t)$ is convex, we have $x_{1} \in \operatorname{Fix}(t)$. Let $y_{1} \in T\left(x_{1}\right)$ such that $\left\|y_{0}-y_{1}\right\|=$ $\operatorname{dist}\left(y_{0}, T\left(x_{1}\right)\right)$. We get $y_{1} \in \operatorname{Fix}(t)$ since $t$ satisfies condition $(K)$. Put

$$
x_{2}=(1-\lambda) x_{1}+\lambda y_{1}
$$

Again, choose $y_{2} \in T\left(x_{2}\right)$ such that $\left\|y_{1}-y_{2}\right\|=\operatorname{dist}\left(y_{1}, T\left(x_{2}\right)\right)$. Similarly, we get $y_{2} \in \operatorname{Fix}(t)$. We have a sequence $\left\{x_{n}\right\} \subseteq \operatorname{Fix}(t)$ such that

$$
x_{n+1}=(1-\lambda) x_{n}+\lambda y_{n}
$$

where $y_{n} \in T\left(x_{n}\right) \cap \operatorname{Fix}(t)$ and $\left\|y_{n-1}-y_{n}\right\|=\operatorname{dist}\left(y_{n-1}, T\left(x_{n}\right)\right)$. For every natural number $n \geq 1$, we have

$$
\left\|x_{n+1}-x_{n}\right\|=\lambda\left\|x_{n}-y_{n}\right\|
$$


It follows that

$$
\lambda \operatorname{dist}\left(x_{n}, T\left(x_{n}\right)\right) \leq \lambda\left\|x_{n}-y_{n}\right\|=\left\|x_{n+1}-x_{n}\right\| .
$$

Since $T$ satisfies condition $\left(C_{\lambda}\right)$, we have

$$
H\left(T\left(x_{n}\right), T\left(x_{n+1}\right)\right) \leq\left\|x_{n}-x_{n+1}\right\| .
$$

Hence, for each $n \geq 1$, we have

$$
\left\|y_{n}-y_{n+1}\right\|=\operatorname{dist}\left(y_{n}, T\left(x_{n+1}\right)\right) \leq H\left(T\left(x_{n}\right), T\left(x_{n+1}\right)\right) \leq\left\|x_{n}-x_{n+1}\right\| .
$$

We now apply Lemma 2.5 to conclude that $\lim _{n \rightarrow \infty}\left\|x_{n}-y_{n}\right\|=0$. That is, as $n \rightarrow \infty$,

$$
\operatorname{dist}\left(x_{n}, T\left(x_{n}\right)\right) \leq\left\|x_{n}-y_{n}\right\| \rightarrow 0 \text {. }
$$

Passing through a subsequence, if necessary, we can assume that $\left\{x_{n}\right\}$ is regular. Let $A\left(\operatorname{Fix}(t),\left\{x_{n}\right\}\right)=\{z\}$. For each $n \geq 1$, we choose $z_{n} \in T(z)$ such that $\left\|x_{n}-z_{n}\right\|=\operatorname{dist}\left(x_{n}, T(z)\right)$. Since $t$ satisfies condition $(K)$, we have $z_{n} \in \operatorname{Fix}(t)$. The compactness of $T(z)$ implies that the sequence $\left\{z_{n}\right\}$ has a convergent subsequence $\left\{z_{n_{k}}\right\}$ with the limit point $w \in T(z)$. We also obtain $w \in \operatorname{Fix}(t)$ since $\operatorname{Fix}(t)$ is closed. By the condition $(E)$ of $T$, we have for some $\mu \geq 1$,

$$
\operatorname{dist}\left(x_{n_{k}}, T(z)\right) \leq \mu \operatorname{dist}\left(x_{n_{k}}, T\left(x_{n_{k}}\right)\right)+\left\|x_{n_{k}}-z\right\| \text {. }
$$

Note that

$$
\left\|x_{n_{k}}-w\right\| \leq\left\|x_{n_{k}}-z_{n_{k}}\right\|+\left\|z_{n_{k}}-w\right\| \leq \mu \operatorname{dist}\left(x_{n_{k}}, T\left(x_{n_{k}}\right)\right)+\left\|x_{n_{k}}-z\right\|+\left\|z_{n_{k}}-w\right\| .
$$

These entail

$$
\limsup _{k \rightarrow \infty}\left\|x_{n_{k}}-w\right\| \leq \limsup _{k \rightarrow \infty}\left\|x_{n_{k}}-z\right\|
$$

Since $\left\{x_{n}\right\}$ is regular, and an asymptotic center of a bounded sequence in a uniformly convex Banach space is a singleton set, these show that $z=w \in T(z)$. Hence, $z=t(z) \in$ $T(z)$.

As a consequence of Proposition 3.1, Proposition 3.2, and Theorem 3.4, we obtain the following corollaries.

Corollary 3.5 Let E be a nonempty bounded closed convex subset of a uniformly convex Banach space $X$. Let $t: E \rightarrow E$ be a quasi-nonexpansive mapping, and let $T: E \rightarrow \mathrm{KC}(E)$ be a multivalued mapping satisfying conditions $(E)$ and $\left(C_{\lambda}\right)$ for some $\lambda \in(0,1)$. If $t$ and $T$ are commute, then they have a common fixed point, that is, there exists a point $z \in E$ such that $z=t(z) \in T(z)$. 
Corollary 3.6 Let E be a nonempty bounded closed convex subset of a uniformly convex Banach space X. Let $t: E \rightarrow$ E be an asymptotically nonexpansive mapping, and let $T: E \rightarrow$ $\mathrm{KC}(E)$ be a multivalued mapping satisfying conditions $(E)$ and $\left(C_{\lambda}\right)$ for some $\lambda \in(0,1)$. If $t$ and $T$ are commute, then they have a common fixed point, that is, there exists a point $z \in E$ such that $z=t(z) \in T(z)$.

\begin{abstract}
Author details
'Department of Mathematics, Faculty of Science, Burapha University, Chonburi, 20131, Thailand. ${ }^{2}$ Department of Mathematics, Faculty of Science, Chiang Mai University, Chiang Mai, 50200, Thailand. ${ }^{3}$ Department of Mathematics, Faculty of Science and Technology, Muban Chombueng Rajabhat University, Ratchaburi, 70150, Thailand.
\end{abstract}

\title{
Acknowledgements
}

The first author would like to thank the Office of the Higher Education Commission, Thailand, for supporting grant fund under the program of Strategic Scholarships for Frontier Research Network for the PhD Program, Thai Doctoral degree, for this research.

Received: 27 April 2012 Accepted: 11 September 2012 Published: 3 October 2012

\section{References}

1. Itoh, S, Takahashi, W: The common fixed point theory of singlevalued mappings and multivalued mappings. Pac. J. Math. 79, 493-508 (1978)

2. Dhompongsa, S, Kaewcharoen, A, Kaewkhao, A: The Dominguez-Lorenzo condition and multivalued nonexpansive mappings. Nonlinear Anal. 64, 958-970 (2006)

3. Dhompongsa, S, Kaewkhao, A, Panyanak, B: Lim's theorems for multivalued mappings in CAT(0) spaces. J. Math. Anal. Appl. 312, 478-487 (2005). doi:10.1016/j.jmaa.2005.03.055

4. Shahzad, N, Markin, J: Invariant approximations for commuting mappings in CAT(0) and hyperconvex spaces. J. Math. Anal. Appl. 337, 1457-1464 (2008). doi:10.1016/j.jmaa.2007.04.041

5. Shahzad, N: Fixed point results for multimaps in CAT(0) spaces. Topol. Appl. 156, 997-1001 (2009). doi:10.1016/j.topol.2008.11.016

6. Suzuki, T: Fixed point theorems and convergence theorems for some generalized nonexpansive mapping. J. Math. Anal. Appl. 340, 1088-1095 (2008). doi:10.1016/j.jmaa.2007.09.023

7. Garcia-Falset, J, Lorens-Fuster, E, Suzuki, T: Fixed point theory for a class of generalized nonexpansive mappings. J. Math. Anal. Appl. 375, 185-195 (2011). doi:10.1016/j.jmaa.2010.08.069

8. Abkar, A, Eslamian, M: Common fixed point results in CAT(0) spaces. Nonlinear Anal. TMA 74, 1835-1840 (2011). doi:10.1016/j.na.2010.10.056

9. Laowang, W, Panyanak, P: Common fixed points for some generalized multivalued nonexpansive mappings in uniformly convex metric spaces. Fixed Point Theory Appl. 2011, 20 (2011)

10. Clarkson, JA: Uniformly convex spaces. Trans. Am. Math. Soc. 40, 396-414 (1936)

11. Xu, HK: Inequalities in Banach spaces with applications. Nonlinear Anal. TMA 16, 1127-1138 (1991)

12. Goebel, K, Kirk, WA: Topics in Metric Fixed Point Theory. Cambridge University Press, Cambridge (1990)

13. Goebel, K: On a fixed point theorem for multivalued nonexpansive mappings. Ann. Univ. Mariae Curie-Skłodowska, Sect. A 29, 70-72 (1972)

14. Lim, TC: A fixed point theorem for multivalued nonexpansive mappings in a uniformly convex Banach space. Bull. Am. Math. Soc. 80, 1123-1126 (1974)

15. Goebel, K, Kirk, WA: Iteration processes for nonexpansive mapping in a Banach space. Contemp. Math. 21, 115-123 (1983)

16. Diaz, JB, Metcalf, FT: On the structure of the set of subsequential limit points of successive approximations. Bull. Am. Math. Soc. 73, 516-519 (1967)

17. Dotson, WG: Fixed points of quasi-nonexpansive mappings. J. Aust. Math. Soc. 13, 167-170 (1972)

18. Goebel, K, Kirk, WA: A fixed point theorem for asymptotically nonexpansive mappings. Proc. Am. Math. Soc. 35 171-174 (1972)

doi:10.1186/1687-1812-2012-171

Cite this article as: Akkasriworn et al.: Common fixed-point results in uniformly convex Banach spaces. Fixed Point Theory and Applications 2012 2012:171. 